\title{
The Relationship between Child Stress, Child Mindfulness and Parent Mindfulness
}

\author{
Lea Waters \\ Melbourne Graduate School of Education, University of Melbourne, Melbourne, Australia \\ Email: I.waters@unimelb.edu.au
}

Received 20 November 2015; accepted 11 January 2016; published 14 January 2016

Copyright (C) 2016 by author and Scientific Research Publishing Inc.

This work is licensed under the Creative Commons Attribution International License (CC BY).

http://creativecommons.org/licenses/by/4.0/

(c) (i) Open Access

\begin{abstract}
The current study tested the degree to which mindfulness in parents was directly and indirectly related to stress levels in children. A community sample of 68 parent-child dyads completed selfreport surveys (Children: $M_{\text {age }}=10.70, S D=2.6 ; 52 \%$ female, $48 \%$ male; Parents: $M_{\text {age }}=42.70, S D=$ 9.6; $72 \%$ female, $28 \%$ male). Multiple regression analyses revealed that both parent mindfulness and child mindfulness were significantly and negatively related to child stress levels. However, mindfulness in children did not mediate the relationship between mindfulness in parents and stress in children. This study contributes to the emerging literature on the effects of mindful parenting on child wellbeing and provides practical suggestions for how parents and children can increase their mindfulness.
\end{abstract}

\section{Keywords}

Parenting, Mindfulness, Stress, Relationships, Psychological Health

\section{Introduction}

Childhood stress has become an area of concern for psychologists, teachers and parents alike. In America, 20\% of children report that they worry a lot or a great deal (American Psychological Association, 2010). In Brazil stress prevalence in children is at $18.2 \%$ (Sbaraini \& Schermann, 2008). In Australia 31\% of students feel "very stressed", $40 \%$ feel that they worry too much and $40 \%$ report that they have difficulty staying calm (Bernard, Stephanau, \& Urbach, 2007). In Pakistan, 57.6\% of female adolescents scored above the midpoint of a stress measure (Parpio, 2013).

Research also suggests that children are experiencing high rates of psychosomatic stress symptoms. For example, in China, 32\% of primary school children report experiencing headaches and 37\% report abdominal pain at least once per month (Hesketh et al., 2010). A nationally representative sample in Sweden found that 21.8\% 
of Swedish children aged 10 - 18 report at least two psychosomatic symptoms (headache, stomach ache, and difficulty falling asleep) per week. Turning to rates of distress more generally across eight European countries, 35\% - 56\% of children aged 4 to 11.8 years report at least one psychosomatic or emotional symptom of stress weekly (Vanaelst et al., 2012).

Stress typically arises when a person perceives that they cannot adequately cope with the demands being placed upon them (Lazarus \& Folkman, 1984; Lazarus, 1966). In other words, stress is caused by a mismatch between demands and resources, rather than the demands of the environment itself (Cox, 1978). This understanding of stress is pertinent to the mental health of children given that they have not yet fully developed the physical, psychological and social resources that enable them to cope with the demands that are being placed upon them. Indeed, children regularly find themselves in situations where the demands and pressures of their environment exceed their resources and ability to cope, (e.g. conflict with parents, academic pressure, cyber bullying) thus causing stress.

\subsection{Mindfulness and Stress}

Mindfulness techniques are increasingly being used to manage childhood stress (Waters, Barsky, Ridd, \& Allen, 2015). Mindfulness can be conceptualized as a present-focused, open, and non-judgmental state of attention and awareness (Brown \& Ryan, 2003; Kabat-Zinn, 1994; Sedlmeier et al., 2012). Departing from its Buddhist roots, mindfulness has become a mainstream stress-management technique in Western societies (see Sun, 2014, for a historical perspective on the "mindfulness movement"). Research shows that secular mindfulness meditation programs reduce stress and anxiety while improving physical health and mental health (for reviews, see Brown, Ryan, \& Creswell, 2007; Khoury et al., 2013). These findings have been demonstrated in clinical and non-clinical populations in adults (Baer, 2003; Grossman, Niemann, Schmidt, \& Walach, 2004; Slagter, Davidson, \& Lutz, 2011) and youth alike (Campion \& Rocco, 2009; Napoli, Krech, \& Holley, 2005; Mendelson et al., 2010).

Mindful attention differs from regular attention along two dimensions: time and breadth (Dane, 2011). With respect to time, mindful attention has a present moment focus and is characterized by the person giving their full attention to the here and now. This type of attention is distinguished against other types of attention such as rumination or prospection that are focused in either the past or the future (Brown \& Ryan, 2003).

With respect to breadth, mindfulness features "wide-open" attention that allows the individual to be "attuned to a relatively large number of external and internal phenomena” (Dane, 2011: p. 1001; Ansburg \& Hill, 2003; Kasof, 1997; Memmert, 2007). Mindful attention allows an individual to simultaneously experience a wide array of information such as their own thoughts, feelings, and bodily sensations together with a host of external stimuli (Slagter et al., 2007; Slagter, Lutz, Greishcar, Nieuwenhuis, \& Davidson, 2009). Research shows that when people are in a mindful state this increases the number of stimuli they notice in their inner world and external environment (Brown \& Ryan, 2003; Dane \& Pratt, 2009; Slagter et al., 2007). The breadth dimension of mindful attention distinguishes it against other states of attention such as flow and fantasy because these states require the person to focus on one object of attention rather than remaining open to what arises.

Mindfulness has the potential to beneficially alter a child's appraisal of their resources and demands thus influencing the experience of stress (Lazarus \& Folkman, 1984). By clearly observing present-moment reactions, children can become aware of the appraisal they have made of the situation and the thoughts that are causing them to feel distress (Duncan, Coatsworth, \& Greenberg, 2009). By giving greater control over one’s attention, mindfulness means that children can look at the situation in a "wide-open" manner. Rather than defaulting to an automatic stress reaction, mindfulness enables children to take into account all of the available information about the situation including about their own thoughts, feelings and sensations (Duncan et al., 2009; Kaiser Greenland, 2010; Napthali, 2003).

Bishop and colleagues (2004) suggest that the non-judgemental aspect of mindfulness helps individuals to adopt a stance of acceptance toward stressful thoughts and feelings. In turn, changing the meaning of emotionally distressing experiences reduces their unpleasant and aversive qualities. In short, mindfulness could help children to appraise a situation as less demanding and/or to provide the mental space to clearly understand the resources they can bring to the situation.

Mindfulness may therefore be used as a mental resource that helps children to cope with stress more effectively. Indeed, research on the effects of mindfulness programs taught to school students has shown that such programs significantly reduce stress and anxiety (see Waters et al., 2015, for a recent review). Mindfulness has also been found to increase calmness, restful alertness, emotional regulation, and relaxation in children and tee- 
nagers (Campion \& Rocco, 2009; Broderick \& Metz, 2009; Mendelson et al., 2010). The research above motivates Hypothesis 1.

Hypothesis 1: Mindfulness in children will be significantly, negatively, related to stress.

\subsection{Mindful Parenting and Child Wellbeing}

Numerous scholars have suggested that mindfulness is an important aspect of effective parenting and has positive effects on child wellbeing (Bluth \& Wahler, 2011; Dumas, 2005; Eyberg \& Graham-Pole, 2005; Kabat-Zinn \& Kabat-Zinn, 1997; Sawyer, 2007; Siegel, 2001; Steinberg, 2004). A recent conceptual model of mindful parenting (Duncan et al., 2009) proposes that mindful parenting is characterized by mindful listening, emotional awareness, compassion and nonjudgmental acceptance in order for the parent to bring moment-to-moment awareness to their interactions with their child. According to Duncan et al. (2009), when parents approach their interactions with their child using mindful awareness they "cultivate an enhanced capacity for parenting calmly... while engendering a warm and nurturing affective tenor" (p. 261). Duncan et al. reason that mindfulness in parents promotes greater trust and emotional sharing between a parent and a child, thus leading to greater wellbeing for both parties.

Mindfulness in parents has become a popular topic of interest in non-academic circles. The development of mindful parenting courses (e.g., Mindful Awareness Parenting ${ }^{\mathrm{TM}}$; http://www.maplinc.com.au) and the publication of self-help parenting books on mindful parenting (Bögels \& Restifo, 2015; Danaan, 2015; Napthali, 2003, 2009a, 2009b; Siegel \& Hartzell, 2004; Race, 2014) point to the emerging demand for practical guidance on applying mindful parenting.

Yet, despite this substantial interest, empirical evidence of the effects of parents' mindfulness on child wellbeing is sparse. Only 9 studies have been published on this topic, 7 of which were focused on treatment settings with children who have externalizing disorders such as ADHD, oppositional-defiant disorder, conduct disorder, and/or autism-spectrum disorder (Bögels et al., 2008; de Bruin, 2014; Ferraioli \& Harris, 2013; Lilly \& Tungol, 2015; Singh et al., 2006, 2007, 2010, 2014) ${ }^{1}$.

Studies in clinical settings have found that mindful parenting helps to reduce child behavior problems, externalizing problems, aggression, and rumination, and is positively related to quality of life (Bögels et al., 2008; de Bruin, 2014; Ferraioli \& Harris, 2013; Lilly \& Tungol, 2015; Singh et al., 2006, 2007, 2011). However, while such findings are encouraging, they cannot be generalized to non-clinical samples.

Only two studies on mindful parenting in non-clinical samples were identified, with mixed results. Altmaier and Maloney (2007) explored the effect of mindful parent training in families of preschoolers who had recently become divorced, but found no changes in the quality of parent-child relationship from pre to post test. In a community sample of parents and teens, however, Coatsworth, Duncan, Greenberg, and Nix (2010) found a significant relationship between parent mindfulness with teenager's positive affect/behavior towards their mothers (e.g., acting lovingly and affectionate towards their mother) and quality of the adolescent-parent relationships. Neither of these studies investigated effects on stress in children.

Clearly, more research is needed to examine the effect of mindfulness in parents on child stress. The current study will test the extent to which child mindfulness mediates the relation between parent mindfulness and reduced stress in children (see Figure 1). This mechanism is based on the possibility that mindful parents may role model mindful behaviors, thereby cultivating mindfulness in their children.

\subsection{Direct Pathway between Mindfulness in Parents and Stress in Children}

Research shows that when parents are coping well, have high self-efficacy and are happy, caring and affectionate, this relates positively to child wellbeing, child adjustment, child behavior and socio-emotional functioning (Coleman \& Karraker, 2003; Jones \& Prinz, 2005; Schwartz, Dudgeon, Sheeber, Yap, Simmons, \& Allen, 2012). In contrast, when parents are highly stressed, they become colder, more controlling, more rejecting and more reactive towards their children leaving negative effects on their children (Belsky, 1984; Webster-Stratton, 1990).

Given the finding of a positive relationship between mindfulness, stress and coping in parent samples (Dawe \& Harnett, 2007), one could speculate that higher levels of mindfulness lead to higher levels of coping and lower levels of stress in parents. Bögels, Lehtonen and Restifo (2010) suggest that mindfulness reduces parental

\footnotetext{
${ }^{1}$ Three other studies were found on mindful parenting. But these studies did not measure child outcomes and focused only on the effects of
} the program for the parents (Dawe \& Harnett, 2007; Vieten, \& Astin, 2008; Williams \& Wahler, 2010). 


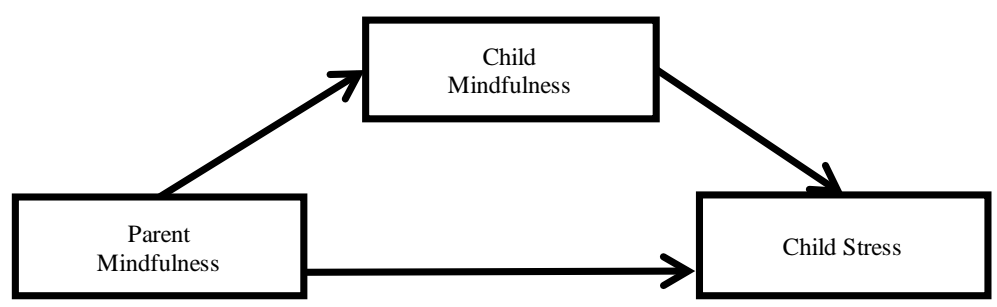

Figure 1. Mediation model for mindful parenting as a mediator of the relationship between mindfulness and stress in children.

reactivity to stress because it allows for parents to become aware of their automatic emotional patterns and to stop and pause before they react with anger, stress or frustration towards their children. Dumas (2005) states that "Parents and children are most likely to call on overlearned ways of coping when they are stressed or distracted (i.e., when their personal resources allow them to do little more than rely on what they know best because they have repeatedly practiced it in the past)” (p. 781). Mindfulness in parents may therefore help to create a calm family environment, which reduces stress in children.

Along similar lines, mindfulness in parents may directly reduce stress in children by fostering a secure attachment between the parent and the child (Siegel, 2001; Siegel \& Hartzell, 2004). Parents who can remain aware and accepting of their child's emotions through using mindfulness practices may be more child-centered (less self/parent-focused) which allows them to meet the child’s needs (Dix, 1991; Dix \& Branca, 2003). The stance of acceptance taken in mindfulness (Roemer \& Orsillo, 2002) may assist the parent to be open and receptive to the child's thoughts, feelings, and sensations (Hayes, Strosahl, \& Wilson, 1999).

One can also imagine that mindfulness allows a parent to become aware of how their own agenda and projections potentially block them from accepting their children for who they are (and not who the parent wants them to be), thus leading to a richer, more authentic relationship between parent and child. Given that secure attachment is a critical aspect of allowing a child to be feel safe (i.e., not stressed) it is probable that mindfulness in parents reduces stress in children because it assists a secure attachment between the parent and the child.

Hypothesis 2: Levels of mindfulness in parents will be significantly, negatively related to levels of stress in children.

\subsection{Indirect Pathway between Mindfulness in Parents and Stress in Children}

In the current study it is proposed that child stress will be inversely related to child mindfulness and that a child's propensity to be mindful will be positively influenced by their parent's level of mindfulness. According to Bandura's (1977) social learning theory, individuals learn by observing the behavior of credible role models. In support of this, Goodman and Gotlib (1999) suggest that children acquire cognitive, behavioral, and affective patterns that resemble their parents' coping styles through social learning and modeling. Such a modeling effect has already been found in relation to various aspects of parent-child coping styles such as self-efficacy (Goodman \& Gotlib, 1999; Jones \& Prinz, 2005). For example, Coleman and Karraker (2003) found that parent selfefficacy was related to child coping patterns, and Bogenschneider, Small and Tsay (1997) found that adolescent girls of parents with higher parent self-efficacy tended to show greater support-focused coping approaches (e.g., seeking out parents to converse about personal problems). Furthermore, emotional states of parents have also been shown to affect the emotional states of their teenaged children (Kim, Conger, Lorenz, \& Elder, 2001). Children may therefore emulate the mindful behaviors of their parents, which indirectly reduce their stress levels, thus leading to Hypotheses three and four below.

Hypothesis 3: Levels of mindfulness in parents will be significantly, positively related to levels of mindfulness in children.

Hypothesis 4: Levels of stress in children will be indirectly related to the levels of mindfulness in parents, through the effect of parent mindfulness on child mindfulness.

\section{Method}

\subsection{Participants and Procedure}

A community sample of Australian upper primary school-aged children $\left(N=68 ; M_{\text {age }}=10.70, S D=2.6 ; 52 \%\right.$ 
female, $48 \%$ male) and one of their parents ( $N=68$; $M_{\text {age }}=42.70, S D=9.6$; $72 \%$ female, $28 \%$ male) participated in this study. Participants were recruited through stress-management workshops that were facilitated by the researcher (a registered psychologist).

This study used a cross-sectional, matched-dyad design with self-report surveys from parents and children. At the start of the workshop, parents completed a brief survey that assessed their levels of mindfulness, while children completed a brief survey that assessed their levels of stress and mindfulness. The researcher then facilitated a discussion with the children and parents about their survey responses, before introducing children to a series of stress management activities and mindfulness practices.

\subsection{Measures}

Mindfulness in parents and children. The Cognitive and Affective Mindfulness Scale-Revised was used to measure mindfulness (CAMS-R; Feldman, Hayes, Kumar, Greeson, \& Laurenceau, 2007). The scale consists of 12 items (e.g., it is easy for me to concentrate on what I am doing; I try to notice my thought without judging them) that were answered on a 5-point Likert scale $(1=$ strongly disagree; $5=$ strongly agree $)$. The scale has been shown to have good reliability and validity (Feldman et al., 2007). In the current study, Cronbach alpha reliability was 0.78 for parents and 0.76 for children.

Stress in children. The stress subscale of the Depression, Stress and Anxiety Scales (DASS) was used (Lovibond \& Lovibond, 1995). The stress subscale consists of 14 items such as "I find it hard to calm down after something upsets me" and "I use a lot of nervous energy". The children were asked to rate how well each statement described them on a 5 -point Likert scale $(1=$ strongly disagree; 5 = strongly agree $)$. This scale has been used in other child and adolescent samples and has shown acceptable psychometric properties (Duffy, Cunningham, \& Moore, 2005; Szabó \& Lovibond, 2006; Szabó, 2010). In an Australian sample, Patrick, Dyck, and Bramston (2010) report Cronbach alpha reliability ranging from 0.94 - 0.96 in children of the same age as the current study. Cronbach alpha reliability in the current sample was 0.87 .

\subsection{Statistical Analysis}

The study hypotheses were tested via correlation analysis and multiple regression analysis. In particular, the current study tested a mediated model for the direct and indirect effects of a parent's level of mindfulness on their child's levels of stress and mindfulness. The idea in mediation analysis is that some of the effect of the independent variable is transmitted to the dependent variable through a mediator variable. In addition, some of the effect of the independent variable passes directly to the dependent variable. That portion of the effect of the independent variable that passes through the mediator variable is the indirect effect (Aiken \& West, 1991; MacKinnon, 2008; MacKinnon \& Luecken, 2008). In this study, it was predicted that mindfulness in parents has a direct, negative relationship with stress and also has an indirect effect on stress through its positive relationship on children's' mindfulness.

\section{Results}

Correlation analysis found that children's stress levels were significantly, negatively related to their levels of mindfulness $(r=-0.43, p<0.01)$ and were significantly, negatively related to their parents ratings levels of mindfulness $(r=-0.30, p<0.05)$. Children's levels of mindfulness and were significantly, positively related to their parent's ratings of mindfulness $(r=0.42, p<0.01)$.

The regression analysis followed Baron and Kenny (1986) and Kenny, Kashy, and Bolger's (1998) four-step causal mediation model. First, according to this model, there must be a significant relationship between the independent variable to the dependent variable. In the current study mindfulness in parents was significantly, negatively related to stress in children, $\beta=-0.29, t(67)=-2.56, p<0.01$, and accounted for $8 \%$ of the variance.

Second, there must be a significant relationship of the independent variable to the hypothesized mediating variable. This step was supported in the current analysis as mindfulness in parents was significantly, positively related to mindfulness in children, $\beta=0.42, t(67)=3.80, p<0.001$, accounting for $15 \%$ of the variance in mindfulness in children.

Third, the mediating variable must be significantly related to the dependent variable. In the current study, mindfulness in children was significantly, negatively related to their reported levels of stress, $\beta=-0.43, t(67)=$ $-3.84, p<0.001$, explaining $17 \%$ of the variance. 
Fourth, when both the independent variable and mediating variable are entered as predictors of the dependent variable, the model requires that the coefficient relating the independent variable to the dependent variable must be smaller than it was in Step 1 . This was supported $\left(\beta_{\text {Step } 1}=-0.29 ; \beta_{\text {Step } 4}=-0.15\right)$. However, the mediation model must also show that the coefficient relating the independent variable to the dependent variable must be larger (in absolute value) than the coefficient relating the mediating variable to the dependent variable. This was not supported as mindfulness in parents had a lower Beta coefficient $(\beta=-0.15)$ than mindfulness in children ( $\beta$ $=-0.35$ ). Moreover, when both mindfulness in parents and mindfulness in children were added into the equation, only mindfulness in children remained significant. Thus, although mindfulness in parents has a significant, direct effect on stress levels in their children, there was no support for the hypothesis that mindfulness in parents reduced stress levels in children via its effects on mindfulness in children (Figure 2).

\section{Discussion}

Past research has shown that parents contribute a role in either diminishing or increasing stress levels in their children (Power, 2004; Waters, 2015). Accordingly, the current study tested the degree to which mindfulness in parents was directly and indirectly related to stress through its influence on the child's levels of mindfulness. Results of this study revealed that both parent and child mindfulness were significantly and negatively related to child stress levels. However, mindfulness in children did not mediate the relationship between mindfulness in parents and stress in children.

With regards to hypothesis one, mindfulness in children was significantly and negatively related to their stress levels. This finding is consistent with past research in which mindfulness has been shown to reduce stress and anxiety as well as increase calmness, restful alertness, emotional regulation, and relaxation in children and teenagers (Campion \& Rocco, 2009; Broderick \& Metz, 2009; Mendelson et al., 2010).

Stress is typically brought about by an imbalance in demands and resources arising when a child perceives that they cannot adequately cope with the demands being placed upon them (Lazarus \& Folkman, 1984; Lazarus, 1966). Successful adaptation to stress involves the ability to 1) accurately understand the current demands and 2) draw on one's resources in order to manage one's emotions, think clearly and regulate one's behavior. Mindfulness keeps a child's attention focused on the present moment which means they can see their current demands clearly, rather than thinking about similar stressors in the past or what the stressor means for them in the future. Mindfulness also cultivates an orientation of acceptance and openness towards present-moment experiences, which reduces the chance of the child responding in a habitual, inflexible, reactive manner and increases their chances of accessing the resources they can draw upon.

In times of stress, one of the resources that children can draw upon is their relationship with their parents (Dumas \& LaFreniere, 1993). Indeed, the second finding of the current study was that children who had more mindful parents reported lower levels of stress. These results suggest that mindful parenting may help children to cope with stress. Such findings are consistent with past research by Bernard et al. (2007) who found that children with higher levels of social and emotional well-being reported that they had parents who were more likely to accept them for who they were, accommodate their interests and make time for them; all features of a mindful parent as defined by Duncan et al. (2009).

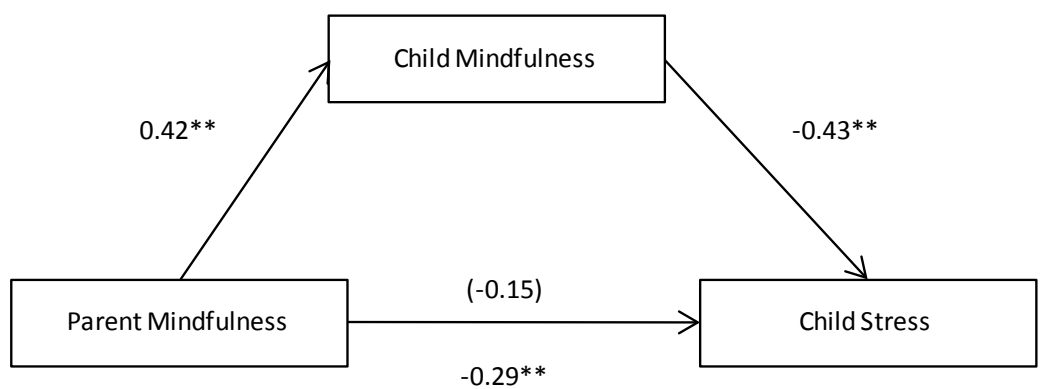

Figure 2. Results of mediation analysis. The number inside parentheses is the standardized coefficient and represents the coefficient when the dependent variable was regressed on the independent variable together with the mediating variable (mindfulness in children). 
Though many parents are likely to understand the importance of providing love and emotional support to their children (Eshel, Daelmans, de Mello, \& Martines, 2006), they may be less aware of the benefits of being able to regulate their attention to be present with and accepting of their children.

The finding that child and parent levels of mindfulness were both inversely related to the child's levels of stress indicates that children would benefit from developing their own mindfulness skills and also from their parents developing mindfulness skills. Although some people are naturally more mindful than others (Baer, 2011; Brown \& Ryan, 2004), all children and parents can learn to become more mindful with practice (KabatZinn, 2005).

One way to improve one's capacity for mindfulness is through enrolling in mindfulness programs. Mindful parenting programs run in clinical settings or community organizations have been shown to successfully teach parents mindfulness (e.g., Altmaier \& Maloney, 2007; Coatsworth et al., 2010). Similarly, children and teens who complete clinical or school-based mindfulness programs report higher levels of mindful states after attending the program (Altmaier \& Maloney, 2007; Coatsworth et al., 2010; Waters et al., 2015).

Besides formal programs, parents can also use additional resources to build their own mindful attention and to help their child develop mindfulness. Several websites and smartphone Apps offer guided and unguided mindfulness exercises including "bite size” exercises that take only 2 - 5 minutes (e.g., http://www.calm.com; http://smilingmind.com.au/smiling-mind-programs; http://www.1giantmind.org; https://www.happify.com; https://www.headspace.com/headspace-meditation-app; http://www.zmeditations.com).

There are books dedicated to helping parents become more mindful including Mindful Parenting (Race, 2014), Everyday Blessings (Kabat-Zinn \& Kabat-Zinn, 1997), Mindful Parenting (Bogels \& Restifo, 2015), Buddhism for Mothers (Napthali, 2003), Buddhism for Mothers of School Children (Napthali, 2009a), Buddhism for Mothers of Young Children (Napthali, 2009b), Parenting From the Inside Out (Siegel \& Hartzell, 2004) and Zen and the Path for Mindful Parenting (Danaan, 2015).

Other books focus on increasing mindfulness in children such as the Mindful Child (Kaiser Greenland, 2010), A Handful of Quiet: Happiness in Four Pebbles (Hanh, 2012), A Boy and a Bear: The Children's Relaxation Book (Lite, 1996), Peaceful Piggy Meditation (MacLean, 2004), Moody Cow Meditates (MacLean, 2009) and Sitting Still Like a Frog: Mindfulness Exercises for Kids (and Their Parents) (Snel, 2013).

Beyond Apps and books, Russell (2011) encourages parents to bring mindfulness into their daily routine. Daily activities such doing the dishes and making schools lunches can become opportunities for mindfulness.

As well as encouraging parents to bring mindfulness into their daily activities, I also encourage parents to show their children how to bring mindfulness into their daily routines. This includes practicing mindfulness on the bus on the way to school, at the dinner table, or prior to doing their homework, cleaning their teeth, packing their school bag and so on.

\subsection{Methodological Considerations and Future Research}

This study has a number of factors that might limit the generalizability of the results. First, the sample size was small which results in less precise estimates of the population means. A larger sample would increase the precision of these estimates and increase the representativeness of the population (upper primary school children and their parents).

Second, the study used a cross-sectional design with correlational data that precludes causal inferences. Namely, we cannot conclude whether mindful parents foster mindful children, whether mindful children foster mindful parents, or whether a third factor (e.g., personality) connects these variables. Third, the community sample of children was recruited from a stress management workshop. If parents enrolled their children in this workshop because their children were highly stressed, these results might not generalize to children with lower stress levels. However, the mean scores on the DASS were similar to another community sample of young people collected in another Australian sample (Patrick et al., 2010), and were at the mid-point on the DASS survey, which suggests that this is not a strong methodological flaw.

In addition, the study may have suffered from sampling bias given that there is likely to be a self-selection effect of the types of parents and children who sign up for a stress management workshop. For example, the workshop may have attracted children and parents who already had a good relationship and were motivated to build further positive aspects. Alternatively, the workshop may have attracted child-parent pairs who were stressed and struggling with their relationship. If so, this would limit generalizability to parents and children 
whose relationship are not at these two extremes. The sample also had a higher proportion of mothers (72\%) which may limit generalizability to fathers. Future researchers could investigate whether parent gender moderates the relations between parent mindfulness, child mindfulness, and childhood stress.

Notwithstanding these limitations, the study also had a number of strengths including the collection of data from multiple sources (i.e., parents and children) which counters the limitation of common source bias. Finally, this study was the first to examine the effects of mindful parenting on stress in a community sample of children. To date, mindful parenting research has predominantly focused on effects in clinical populations. More research is needed to test the effects of mindfulness in families that function within the normal range because children in the general population still experience stress (American Psychological Association, 2010; Bernard et al., 2007) and could benefit from learning stress management techniques (e.g., mindfulness) and by being surrounded by people (e.g., mindful parents) who can help them alleviate their stress.

\section{Conclusion}

In order to best understand the causes and buffers of childhood stress, researchers need to consider both intrapersonal and interpersonal influences (Bedin \& Sarriera, 2015). Using a dyadic approach, the current study considered the role of a child's own capacity for mindfulness (e.g., an intrapersonal aspect) as well as the role of one parent's levels of mindfulness (e.g., an interpersonal aspect). Children who were more mindful or who had a more mindful parent reported lower levels of stress suggesting that research into how to promote mindfulness in families is a promising area for further exploration.

\section{References}

Aiken, L. S., \& West, S. G. (1991). Multiple Regression: Testing and Interpreting Interactions. Thousand Oaks, CA: Sage.

Altmaier, E., \& Maloney, R. (2007). An Initial Evaluation of a Mindful Parenting Program. Journal of Clinical Psychology, 63, 1231-1238. http://dx.doi.org/10.1002/jclp.20395

American Psychological Association (2010). Stress in America Findings.

https://www.apa.org/news/press/releases/stress/2010/national-report.pdf

Ansburg, P. I., \& Hill, K. (2003). Creative and Analytic Thinkers Differ in Their Use of Attentional Resources. Personality and Individual Differences, 34, 1141-1152. http://dx.doi.org/10.1016/S0191-8869(02)00104-6

Baer, R. A. (2003). Mindfulness Training as a Clinical Intervention: A Conceptual and Empirical Review. Clinical Psychology: Science and Practice, 10, 125-143. http://dx.doi.org/10.1093/clipsy.bpg015

Baer, R. A. (2011). Measuring Mindfulness. Contemporary Buddhism, 12, 241-261. http://dx.doi.org/10.1080/14639947.2011.564842

Bandura, A. (1977). Self-Efficacy: Toward a Unifying Theory of Behavioral Change. Psychological Review, 84, $191-215$. http://dx.doi.org/10.1037/0033-295X.84.2.191

Baron, R. M., \& Kenny, D. A. (1986). The Moderator-Mediator Variable Distinction in Social Psychological Research: Conceptual, Strategic, and Statistical Considerations. Journal of Personality and Social Psychology, 51, 1173-1182. http://dx.doi.org/10.1037/0022-3514.51.6.1173

Bedin, L., \& Sarriera, J. (2015). A Comparative Study of the Subjective Well-Being of Parents and Adolescents Considering Gender, Age and Social Class. Social Indicators Research, 120, 79-95. http://dx.doi.org/10.1007/s11205-014-0589-7

Belsky, J. (1984). The Determinants of Parenting: A Process Model. Child Development, 55, 83-96. http://dx.doi.org/10.2307/1129836

Bernard, M. E., Stephanau, A., \& Urbach, D. (2007). ASG Student Social and Emotional Health Report. https://www.acer.edu.au/files/SEWB_ASG-StudentSocialEmotionalHealthReport.pdf

Bishop, S. R., Lau, M., Shapiro, S., Carlson, L., Anderson, N. D., Carmody, J. et al. (2004). Mindfulness: A Proposed Operational Definition. Clinical Psychology: Science and Practice, 11, 230-241. http://dx.doi.org/10.1093/clipsy/bph077

Bluth, K., \& Wahler, R. G. (2011). Parenting Preschoolers: Can Mindfulness Help? Mindfulness, 2, 282-285. http://dx.doi.org/10.1007/s12671-011-0071-4

Bögels, S., Hoogstad, B., van Dun, L., de Schutter, S., \& Restifo, K. (2008). Mindfulness Training for Adolescents with Externalizing Disorders and Their Parents. Behavioural and Cognitive Psychotherapy, 36, 193-209. http://dx.doi.org/10.1017/S1352465808004190

Bögels, S., \& Restifo, K. (2015). Mindful Parenting: A Guide for Mental Health Practitioners. New York: Springer-Verlag.

Bogenschneider, K., Small, S. A., \& Tsay, J. C. (1997). Child, Parent, and Contextual Influences on Perceived Parenting 
Competence among Parents of Adolescents. Journal of Marriage and the Family, 59, 345-362. http://dx.doi.org/10.2307/353475

Broderick, P. C., \& Metz, S. (2009). Learning to BREATHE: A Pilot Trial of a Mindfulness Curriculum for Adolescents. Advances in School Mental Health Promotion, 2, 35-46. http://dx.doi.org/10.1080/1754730X. 2009.9715696

Brown, K. W., \& Ryan, R. M. (2003). The Benefits of Being Present: Mindfulness and Its Role in Psychological Well-Being. Journal of Personality and Social Psychology, 84, 822-848. http://dx.doi.org/10.1037/0022-3514.84.4.822

Brown. K. W., \& Ryan, R. M. (2003). Perils and Promise in Defining and Measuring Mindfulness: Observations from Experience. Clinical Psychology: Science and Practice, 11, 242-248. http://dx.doi.org/10.1093/clipsy/bph078

Brown, K. W., Ryan, R. M., \& Creswell, J. D. (2007). Mindfulness: Theoretical Foundations and Evidence for Its Salutary Effects. Psychological Inquiry, 18, 211-237. http://dx.doi.org/10.1080/10478400701598298

Campion, J., \& Rocco, S. (2009). Minding the Mind: The Effects and Potential of a School-Based Meditation Programme for Mental Health Promotion. Advances in School Mental Health Promotion, 2, 47-55. http://dx.doi.org/10.1080/1754730X.2009.9715697

Coatsworth, J. D., Duncan, L. G., Greenberg, M. T., \& Nix, R. L. (2010). Changing Parent’s Mindfulness, Child Management Skills and Relationship Quality with Their Youth: Results from a Randomized Pilot Intervention Trial. Journal of Child and Family Studies, 19, 203-217. http://dx.doi.org/10.1007/s10826-009-9304-8

Coleman, P. K., \& Karraker, K. H. (2003a). Maternal Self-Efficacy Beliefs, Competence in Parenting, and Toddlers’ Behavior and Developmental Status. Infant Mental Health Journal, 24, 126-148. http://dx.doi.org/10.1002/imhj.10048

Cox, T. (1978). Stress. Basingstoke: Macmillan Education.

Danaan, C. (2015). Zen \& the Path of Mindful Parenting: Meditations on Raising Children. East Sussex: Leaping Hare Press.

Dane, E. (2011). Paying Attention to Mindfulness and Its Effects on Task Performance in the Workplace. Journal of Management, 37, 997-1018. http://dx.doi.org/10.1177/0149206310367948

Dane, E., \& Pratt, M. G. (2009). Conceptualizing and Measuring Intuition: A Review of Recent Trends. In G. P. Hodgkinson \& J. K. Ford (Eds.), International Review of Industrial and Organizational Psychology (pp. 1-49). Chichester: Wiley.

Dawe, S., \& Harnett, P. (2007). Reducing Potential for Child Abuse among Methadone-Maintained Parents: Results from a Randomized Controlled Trial. Journal of Substance Abuse Treatment, 32, 381-390. http://dx.doi.org/10.1016/j.jsat.2006.10.003

de Bruin, E. I., Blom, R., Smit, F. M., van Steensel, F. J., \& Bögels, S. M. (2014). MYmind: Mindfulness Training for Youngsters with Autism Spectrum Disorders and Their Parents. Autism: The International Journal of Research and Practice, 19, 906-914. http://dx.doi.org/10.1177/1362361314553279

Dix, T. (1991). The Affective Organization of Parenting: Adaptive and Maladaptive Processes. Psychological Bulletin, 110, 3-25. http://dx.doi.org/10.1037/0033-2909.110.1.3

Dix, T., \& Branca, S. (2003). Parenting as a Goal-Regulation Process. In L. Kuczynski (Ed.), Handbook of Dynamics in Parent-Child Relations (pp. 167-188). Thousand Oaks, CA: Sage.

Duffy, C. J., Cunningham, E. G., \& Moore, S. M. (2005). Brief Report: The Factor Structure of Mood States in an Early Adolescent Sample. Journal of Adolescence, 28, 677-680. http://dx.doi.org/10.1016/j.adolescence.2005.08.013

Dumas, J. E. (2005). Mindfulness-Based Parent Training: Strategies to Lessen the Grip of Automaticity in Families with Disruptive Children. Journal of Clinical Child and Adolescent Psychology, 34, 779-791.

http://dx.doi.org/10.1207/s15374424jccp3404_20

Dumas, J. E., \& LaFreniere, P. J. (1993). Mother-Child Relationships as Sources of Support or Stress: A Comparison of Competent, Average, Aggressive, and Anxious Dyads. Child Development, 64, 1732-1754. http://dx.doi.org/10.2307/1131466

Duncan, L. G., Coatsworth, J. D., \& Greenberg, M. T. (2009). A Model of Mindful Parenting: Implications for Parent-Child Relationships and Prevention Research. Clinical Child and Family Psychology Review, 12, 255-270. http://dx.doi.org/10.1007/s10567-009-0046-3

Eshel, N., Daelmans, B., Cabral De Mello, M., \& Martines, J. (2006). Responsive Parenting: Interventions and Outcomes. Bulletin of the World Health Organization, 84, 991-998. http://dx.doi.org/10.2471/BLT.06.030163

Eyberg, S. M., \& Graham-Pole, J. R. (2005). Mindfulness and Behavioural Parent Training: Commentary. Journal of Clinical Child and Adolescent Psychology, 34, 792-794. http://dx.doi.org/10.1207/s15374424jccp3404_21

Feldman, G. C., Hayes, A. M., Kumar, S. M., Greeson, J. G., \& Laurenceau, J. P. (2007). Mindfulness and Emotion Regulation: The Development and Initial Validation of the Cognitive and Affective Mindfulness Scale-Revised (CAMS-R). Journal of Psychopathology and Behavioral Assessment, 29, 177-190. http://dx.doi.org/10.1007/s10862-006-9035-8

Ferraioli, S. J., \& Harris, S. L. (2013). Comparative Effects of Mindfulness and Skills-Based Parent Training Programs for 
Parents of Children with Autism: Feasibility and Preliminary Outcome Data. Mindfulness, 4, 89-101. http://dx.doi.org/10.1007/s12671-012-0099-0

Goodman, S. H., \& Gotlib, I. H. (1999). Risk for Psychopathology in the Children of Depressed Mothers: A Developmental Model for Understanding Mechanisms of Transmission. Psychological Review, 106, 458-490.

http://dx.doi.org/10.1037/0033-295X.106.3.458

Grossman, P., Niemann, L., Schmidt, S., \& Walach, H. (2004). Mindfulness-Based Stress Reduction and Health Benefits. A Meta-Analysis. Journal of Psychosomatic Research, 57, 35-43. http://dx.doi.org/10.1016/S0022-3999(03)00573-7

Hanh, T. N. (2012). A Handful of Quiet: Happiness in Four Pebbles. Berkeley: Plum Blossom Books.

Hayes, S. C., Strosahl, K., \& Wilson, K. G. (1999). Acceptance and Commitment Therapy: An Experiential Approach to Behaviour Change. New York: Guilford Press.

Hesketh, T., Zhen, Y., Lu, L., Dong, Z. X., Jun, Y. X., \& Xing, Z. W. (2010). Stress and Psychosomatic Symptoms in Chinese School Children: Cross-Sectional Survey. Archives of Disease in Childhood, 95, 136-140. http://dx.doi.org/10.1136/adc.2009.171660

Jones, T. L., \& Prinz, R. J. (2005). Potential Roles of Parental Self-Efficacy in Parent and Child Adjustment: A Review. Clinical Psychology Review, 25, 341-363. http://dx.doi.org/10.1016/j.cpr.2004.12.004

Kabat-Zinn, J. (1994). Wherever You Go, There You Are. New York: Hyperion.

Kabat-Zinn, J. (2005). Coming to Our Senses: Healing Ourselves and the World through Mindfulness. New York: Hyperion.

Kabat-Zinn, M., \& Kabat-Zinn, J. (1997). Everyday Blessings: The Inner Work of Mindful Parenting. New York: Hyperion.

Kaiser Greenland, S. (2010). The Mindful Child: How to Help Your Kid Manage Stress and Become Happier, Kinder, and More Compassionate. New York: Free Press.

Kasof, J. (1997). Creativity and Breadth of Attention. Creativity Research Journal, 10, 303-315. http://dx.doi.org/10.1207/s15326934crj1004_2

Kenny, D. A., Kashy, D. A., \& Bolger, N. (1998). Data Analysis in Social Psychology. In D. Gilbert, S. Fiske, \& G. Lindzey (Eds.), The Handbook of Social Psychology (4th ed., pp. 233-265). Boston, MA: McGraw-Hill.

Khoury, B., Lecomte, T., Fortin, G., Masse, M., Therien, P., Bouchard, V., Chapleau, M. A., Paquin, K., \& Hofmann, S. G. (2013). Mindfulness-Based Therapy: A Comprehensive Meta-Analysis. Clinical Psychology Review, 33, 763-771. http://dx.doi.org/10.1016/j.cpr.2013.05.005

Kim, K. J., Conger, R. D., Lorenz, F. O., \& Elder, G. H. (2001). Parent-Adolescent Reciprocity in Negative Affect and Its Relation to Early Adult Social Development. Developmental Psychology, 37, 775-790. http://dx.doi.org/10.1037//0012-1649.37.6.775

Lazarus, R. S. (1966). Psychological Stress and the Coping Process. New York: McGraw-Hill.

Lazarus, R. S., \& Folkman, S. (1984). Stress, Appraisal and Coping. New York: Springer.

Lilly, J., \& Tungol, J. R. (2015). Effectiveness of Mindfulness Based Psycho-Educational Program on Parental Stress of Selected Mothers of Children with Autism. Indian Journal of Positive Psychology, 6, 52-56.

Lite, L. (1996). A Boy and a Bear: The Children's Relaxation Book. Plantation, FL: Specialty Press, Inc.

Lovibond, S. H., \& Lovibond, P. F. (1995). Manual for the Depression Anxiety Stress Scales. Sydney: Psychology Foundation.

MacKinnon, D. P. (2008). Introduction to Statistical Mediation Analysis. New York: Erlbaum.

MacKinnon, D. P., \& Luecken, L. J. (2008). How and for Whom? Mediation and Moderation in Health Psychology. Health Psychology, 27, S99-S100. http://dx.doi.org/10.1037/0278-6133.27.2(Suppl.).S99

MacLean, K. L. (2004). Peaceful Piggy Meditation. Park Ridge, IL: Albert Whitman \& Company.

MacLean, K. L. (2009). Moody Cow Meditates. Somerville, MA: Wisdom Publications.

Memmert, D. (2007). Can Creativity Be Improved by an Attention-Broadening Training Program? An Exploratory Study Focusing on Team Sports. Creativity Research Journal, 19, 281-291. http://dx.doi.org/10.1080/10400410701397420

Mendelson, T., Greenberg, M. T., Dariotis, J. K., Gould, L. F., Rhoades, B. L., \& Leaf, P. J. (2010). Feasibility and Preliminary Outcomes of a School-Based Mindfulness Intervention for Urban Youth. Journal of Abnormal Child Psychology, 38, 985-994. http://dx.doi.org/10.1007/s10802-010-9418-X

Napoli, M., Krech, P. R., \& Holley, L. C. (2005). Mindfulness Training for Elementary School Students: The Attention Academy. Journal of Applied School Psychology, 21, 99-125. http://dx.doi.org/10.1300/J370v21n01_05

Napthali, S. (2003). Buddhism for Mothers: A Calm Approach to Caring for Yourself and Your Children. Sydney: Inspired Living. 
Napthali, S. (2009a). Buddhism for Mothers of Schoolchildren: Finding Calm in the Chaos of the School Years. Sydney: Inspired Living.

Napthali, S. (2009b). Buddhism for Mothers of Young Children. Sydney: Inspired Living.

Parpio, Y. (2013). Prevalence and Associated Factors of Perceived Stress among Adolescent Girls in Nawabshahi City, Pakistan. Journal of Ayub Medical College, 25, 116-119.

Patrick, J., Dyck, M., \& Bramston, P. (2010). Depression Anxiety Stress Scale: Is It Valid for Children and Adolescents? Journal of Clinical Psychology, 66, 996-1007. http://dx.doi.org/10.1002/jclp.20696

Power, T. G. (2004). Stress and Coping in Childhood: The Parents’ Role. Parenting: Science and Practice, 4, 271-317. http://dx.doi.org/10.1207/s15327922par0404_1

Race, K. (2014). Mindful Parenting: Simple and Powerful Solutions for Raising Creative, Engaged, Happy Kids in Today's Hectic World. New York: St Martin’s Griffin.

Roemer, L., \& Orsillo, S. M. (2002). Expanding Our Conceptualization of and Treatment for Generalized Anxiety Disorder: Integrating Mindfulness/Acceptance-Based Approaches with Existing Cognitive-Behavioral Models. Clinical Psychology: Science and Practice, 9, 54-68. http://dx.doi.org/10.1093/clipsy.9.1.54

Russell, J (2011). Mindfulness: A Tool for Parents and Children with Asperger’s Syndrome, Mindfulness, 2, $212-215$. http://dx.doi.org/10.1007/s12671-011-0063-4

Sawyer, J. (2007). Mindful Parenting, Affective Attunement, and Maternal Depression: A Call for Research. Graduate Student Journal of Psychology, 9, 3-9.

Sbaraini, C. R., \& Schermann, L. B. (2008). Prevalence of Childhood Stress and Associated Factors: A Study of Schoolchildren in a City in Rio Grande do Sul State, Brazil. Cad Saúde Pública, 24, 1082-1088.

Schwartz, O. S., Dudgeon, P., Sheeber, L. B., Yap, M. B. H., Simmons, J. G., \& Allen, N. B. (2012). Parental Behaviors during Family Interactions Predict Changes in Depression and Anxiety Symptoms during Adolescence. Journal of Abnormal Child Psychology, 40, 59-71. http://dx.doi.org/10.1007/s10802-011-9542-2

Sedlmeier, P., Eberth, J., Schwarz, M., Zimmermann, D., Haarig, F., Jaeger, S., \& Kunze, S. (2012). The Psychological Effects of Meditation: A Meta-Analysis. Psychological Bulletin, 138, 1139-1171. http://dx.doi.org/10.1037/a0028168

Siegel, D. J. (2001). Toward an Interpersonal Neurobiology of the Developing Mind: Attachment Relationships, “Mindsight,” and Neural Integration. Infant Mental Health Journal, 22, 67-94. http://dx.doi.org/10.1002/1097-0355(200101/04)22:1<67::AID-IMHJ3>3.0.CO;2-G

Siegel, D. J., \& Hartzell, M. (2004). Parenting from the Inside Out. New York: Penguin.

Singh, N. N., Lancioni, G. E., Winton, A. S. W., Fisher, B. C., Wahler, R. G., Mcaleavey, K. et al. (2006). Mindful Parenting Decreases Aggression, Noncompliance, and Self-Injury in Children with Autism. Journal of Emotional and Behavioral Disorders, 14, 169-177. http://dx.doi.org/10.1177/10634266060140030401

Singh, N. N., Lancioni, G. E., Winton, A. S., Singh, J., Curtis, W. J., Wahler, R. G., \& McAleavey, K. M. (2007). Mindful Parenting Decreases Aggression and Increases Social Behavior in Children with Developmental Disabilities. Behavior Modification, 31, 749-771. http://dx.doi.org/10.1177/0145445507300924

Singh, N. N., Lancioni, G. E., Manikam, R., Winton, A. S., Singh, A. N., Singh, J., \& Singh, A. D. (2011). A MindfulnessBased Strategy for Self-Management of Aggressive Behavior in Adolescents with Autism. Research in Autism Spectrum Disorders, 5, 1153-1158. http://dx.doi.org/10.1016/j.rasd.2010.12.012

Singh, N. N., Lancioni, G., Winton, A., Karazsia, B., Myers, R., Latham, L., \& Singh, J. (2014). Mindfulness-Based Positive Behavior Support (MBPBS) for Mothers of Adolescents with Autism Spectrum Disorder: Effects on Adolescents' Behavior and Parental Stress. Mindfulness, 6, 646-657. http://dx.doi.org/10.1007/s12671-014-0321-3

Singh, N. N., Singh, A., Lancioni, G., Singh, J., Winton, A., \& Adkins, A. (2010). Mindfulness Training for Parents and Their Children with ADHD Increases the Children's Compliance. Journal of Child and Family Studies, 19, 157-166.

Slagter, H. A., Davidson, R. J., \& Lutz, A. (2011). Mental Training as a Tool in the Neuroscientific Study of Brain and Cognitive Plasticity. Frontiers in Human Neuroscience, 5, Article No. 17. http://dx.doi.org/10.3389/fnhum.2011.00017

Slagter, L., Greishcar, N., \& Davidson, R. J. (2009). Theta Phase Synchrony and Conscious Target Perception: Impact of Intensive Mental Training. Journal of Cognitive Neuroscience, 21, 1536-1549. http://dx.doi.org/10.1162/jocn.2009.21125

Slagter, H. A., Lutz, A., Greischar, L. L., Francis, A. D., Nieuwenhuis, S., Davis, J. M., \& Davidson, R. J. (2007). Mental Training Affects Distribution of Limited Brain Resources. PLOS Biology, 5, e183. http://dx.doi.org/10.1371/journal.pbio.0050138

Snel, E. (2013). Sitting Still like a Frog: Mindfulness Exercises for Kids (And Their Parents). Boston, MA: Shambhala Publications, Inc.

Steinberg, L. (2004). The 10 Basic Principles of Good Parenting. New York: Simon \& Schuster. 
Sun, J. (2014). Mindfulness in Context: A Historical Discourse Analysis. Contemporary Buddhism, 15, 394-415. http://dx.doi.org/10.1080/14639947.2014.978088

Szabó, M. (2010). The Short Version of the Depression Anxiety Stress Scales (DASS-21): Factor Structure in a Young Adolescent Sample. Journal of Adolescence, 33, 1-8. http://dx.doi.org/10.1016/j.adolescence.2009.05.014

Szabó, M., \& Lovibond, P. F. (2006). Worry Episodes and Perceived Problem Solving: A Diary-Based Approach. Anxiety, Stress \& Coping, 19, 175-187. http://dx.doi.org/10.1080/10615800600643562

Vanaelst, B., De Vriendt, T., Ahrens, W., Bammann, K., Hadjigeorgiou, C., Konstabel, K. et al. (2012). Prevalence of Psychosomatic and Emotional Symptoms in European School-Aged Children and Its Relationship with Childhood Adversities: Results from the IDEFICS Study. European Child \& Adolescent Psychiatry, 21, 253-265. http://dx.doi.org/10.1007/s00787-012-0258-9

Waters, L. (2015). The Relationship between Strength-Based Parenting with Children's Stress Levels and Strength-Based Coping Approaches. Psychology, 6, 689-699. http://dx.doi.org/10.4236/psych.2015.66067

Waters, L., Barsky, A., Ridd, A., \& Allen, K. (2015). Contemplative Education: A Systematic, Evidence-Based Review of the Effect of Meditation Interventions in Schools. Educational Psychology Review, 27, 103-134. http://dx.doi.org/10.1007/s10648-014-9258-2

Webster-Stratton, C. (1990). Stress: A Potential Disruptor of Parent Perceptions and Family Interactions. Journal of Clinical Child Psychology, 19, 302-312. http://dx.doi.org/10.1207/s15374424jccp1904_2

Williams, K. L., \& Wahler, R. G. (2010). Are Mindful Parents More Authoritative and Less Authoritarian? An Analysis of Clinic-Referred Mothers. Journal of Child and Family Studies, 19, 230-235. http://dx.doi.org/10.1007/s10826-009-9309-3 